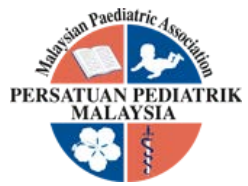

\title{
THE THEORETICAL MODEL OF SCHOOL REFUSAL: THE SELF-EFFICACY CONCEPT
}

\author{
Maruzairi Husain ${ }^{1}, \mathrm{Ng}$ Vi Vien²
}

\begin{abstract}
Introduction: School refusal is a common cause of chronically poor school attendance. The basis of school refusal behaviour can be grouped into the symptomatic and functional models, the operant conditioning model and the cognitive model. Objective: This paper is aimed to discuss the various systems and models which explain the school refusal behaviour. Method: An initial search of published literature in English Language was performed on the online databases including Google Scholar, Science Direct, EBSCOhost, and Proquest with the main keywords were School Refusal and Self-efficacy. Further sources were identified after consulting the original author for recommendations, and references within the literature retrieved in the initial search. Results: Out of 57 articles found, 41 were used in this review. Development and maintenance of school refusal involve heterogeneous risk factors and processes. The existing theoretical basis of school refusal behaviour can be grouped into symptomatic models, the operant conditioning model and the cognitive model. Conclusion: School refusal depicts a symptom, heralding the need for early intervention before development of a more pervasive mental health disorder. Where the problem had persisted for months to years, the child or adolescent would commonly present with coexisting anxiety or depressive disorders.
\end{abstract}

\section{Keywords:}

School Refusal, Self-efficacy, Adolescent

\section{Introduction}

Problematic school attendance amongst students has unremittingly been a major concern in developed and developing countries across the world [1]. Governments and communities at large devote intense attention to the attainment of education in general, and school attendance specifically [2]. Chronically poor school attendance deprives a child from educational opportunities [3], in addition to missing out on basic social, emotional and health services [4]. This potentially preventable phenomena have been invariably linked to negative outcomes, both short- and long-term during ensuing adulthood including negatively affect learning and achievement [3] early school drop-out [5], social withdrawal [6], poor social adjustment [7] as well as psychopathology and mental health problems in late adolescence and adulthood [8,9].
Received: 8 December 2019; Accepted revised manuscript: 16 January 2020

Published online: 29 January 2020
Given the heterogeneous reasons a student may be absent from school, numerous terms and classification systems have been developed to illustrate the problem of persistent school absenteeism. Truancy is unwarranted absenteeism from school that the student intentionally concealed from parental or teachers' awareness [10]. It is different from school refusal whereby the child-motivated reluctance or outright refusal to attend or remain in school $[11,12]$. Another term is school withdrawal/with-

\footnotetext{
1. Department of Psychiatry, School of Medical Sciences, Universiti Sains Malaysia, 16150 Kubang Kerian, Kelantan

2. Department of Psychiatry, Teluk Intan Hospital, Jalan Changkat Jong, 36000 Teluk Intan, Perak

Corresponding author: Dr. Maruzairi Husain,

Department of Psychiatry, School of Medical Sciences,

Universiti Sains Malaysia, 16150 Kubang Kerian, Kelantan.

Email: drzairi@usm.my; Tel: +6097676710
} 
holding which referred to the child being kept away from school deliberately despite being an unauthorised absence in accordance to education acts in most countries $[10,13,14]$.

This taxonomic distinction is vital because 'school refusers' have often been misclassified by education authorities as truants [14]. Evidence from the wealth of earlier research has linked this group of students who refused school with severe emotional distress, but in whom there is an absence of antisocial tendencies and delinquency, thus distinguishing them from truancy $[11,12]$. The lack in awareness that school refusal depicts a symptom [15], and is not in itself a syndrome, leads to delayed detection, unavailability of effective interventions, and encapsulation of comorbidities directly or indirectly associated with the school refusal behaviour. Students referred for assessment because of school refusal behaviours typically present with coexisting conditions like stressor-related, anxiety or depressive disorders $[9,15,16,17]$.

This paper would begin with a chronological reiteration of the phenomena of school refusal behaviour. Various systems and models to explain the school refusal behaviour will be discussed to compare the different tenets. Thereafter, the focus would shift into the theoretical and conceptual groundworks of the self-efficacy concept. It which would be discussed in greater details in the perspective of early adolescence development, and from there linked to school-going experiences.

\section{Method}

An initial search of published literature was performed in August 2014 on the following online databases Google Scholar, Science Direct, EBSCOhost, and Proquest. Literature involved were only those published in English language. Main keywords were sub-grouped into broad themes of School Refusal, Self-efficacy. The following search terms were used on all databases: 'early adolescence', 'school attendance', and 'truancy' and 'school refusal' for the first category. Literature on Self-efficacy used the combination with 'adolescence', 'academic', 'social', and 'school'. Further sources were identified after consulting the original author for recommendations, and references within the literature retrieved in the initial search. Search was repeated for new references in September and October 2016 using the limit 'since 2015'.

\section{Findings}

There were 57 articles found during the literature search and 41 articles had been used in this review. Development and maintenance of a problem like school refusal typically involve heterogeneous risk factors and processes $[1,15,18]$. To conceptualize a case of school refusal, researchers have recommended various assessment methods and procedures, based on hypothesized models that the refusal context is influenced by its clinical diagnostic groupings, functional system of behaviour, and cognitive factors.

\section{Symptomatic and Functional Models}

When school refusal was first described in the twentieth century, it had been grouped under truancy. Two children, aged 9 and 13 years old, were reported to develop a generally sudden change in attitude towards school, from a fair conduct to one of fearfulness and despair, resulting in the child being consistently absent from school for prolonged periods of months to years, opting instead to remain at home [19]. The emphasis conveyed at that point had been that this form of truancy arose from neuroses, obsessional thoughts or urges, and psychodynamic conflicts of the immature ego. The condition was gradually refined and contrasted from delinquent truancy by the change in nosology to school phobia, with the basis that anxiety in the child and a pathological maternalchild relationship underpinned the syndrome [20]. An early study reported that out of 50 children followed-up for persistent non-attendance at school, the mean age was 11.8 years, the majority were the only or youngest child, boys outnumbered girls (62\% and $38 \%$ respectively), mean intelligence quotient (IQ) was 106.4 and presence of parental psychiatric disorders or maladaptive parenting traits [12]. In a narrative review by Lang (1982) [21], an evolving trend in conjecturing the causes of the school refusal behaviour was traced from separation anxiety and over-dependency between mother-child, to subclinical depression in the child and parental psychiatric disorders. He then expanded on the understanding of school refusal by introducing the dysfunctional social system in which difficulties can be identified three levels - the child, the family and the wider social context.

Succeeding studies also support co-morbidity with Diagnostic and Statistical Manual of Mental Disorders (DSM) diagnoses like depressive and anxiety disorders [22,23], and stressor-related 
disorders [17]. Such tenets lead forth to nosologies like 'anxious school refusers', or 'emotionally based school refusal', and will undoubtedly guide treatment of children who refused to attend school due to underlying psychiatric disorders. On the other hand, if management depends solely on clinical classification systems, this will unevitably produce over-medicalization, the ensuing stigma of having the diagnosis of a mental illness, and the child will suffer further ostracization in schools [24].

In the 1990s, there was a shift in the attention towards a functional model that could guide individualized treatment plans of a school refuser. All prior classifications had been symptomsoriented, giving the impression that school refusal is a concrete clinical phenomenon, but without conveying vital information about the more abstract interpersonal interaction system in which the child is immersed in, the motivations that maintain the behaviour and therapeutic effectiveness after appropriate treatment given.

\section{The operant conditioning model}

Applying the operant conditioning principles [25] to the problem of school refusal behaviour, a functional approach based on child-motivation establishes the maintaining variables of school refusal [26]. This hypothesis underlie the development of the School Refusal Assessment Scale [27], which enables measurement of the functional dimensions for a child's refusal to attend school, and sub-classification into positive reinforcers (i.e., attention-getting, positive tangible reinforcement) or negative reinforcers (i.e., avoidance, escape). The Kearney and Silverman's Functional Model of School Refusal contributed tremendously in the advances of research on school refusal. Their introduction of child, parent, and teacher scoring scales to identify reinforcing factors maintaining school refusal behaviour greatly helped guide individualized treatment processes. Nonetheless, school refusal typically involve multiple risk factors and processes, including - but not limited to - the child's incentive to stay away from school; thus rendering Kearney's term child-motivated attendance problems a misnomer. This is examplified in a sample of students referred to social workers for school refusal, three functional profiles were identified - the positively reinforced school refusal profile, multiple (with both positively and negatively reinforced) profile and the group without any specific functional profiles
- therefore providing evidence that these students are manifesting other types of school refusal behaviours may not be child-motivated [28].

The authors of the School Refusal Assessment Scale (SRAS) distinguished negative and positive reinforcements that contributed to maintaining the school refusal behaviour, and these two dimensions correlated well with internalizing/externalizing behaviours as well symptoms of anxiety/depression and oppositional problems respectively [27]. Examples of negative reinforcers which provoke avoidance responses were being afraid of something related to school (e.g. tests), feeling sad when at school and having bad feelings when thinking about school on weekends. Examples of negative reinforcers that would trigger the need to escape the situation were the need to speak with other kids at school, feeling embarrassed in front of others at school and not having many friends in school. Situations like preferring to be with parents than going to school, going to school with accompaniment of parents and preferring to be taught by parents at home fell under positive reinforcements that were related to the pursuit of attention. A final group that reflected the play of positive reinforcement in maintaining the school refusal behaviour were situations in which the child pursued fun things outside school.

\section{The Cognitive Model}

A separate group of therapists postulates that the cognitions of children with school refusal play a key role in the manifestation of the behaviour [29]. Utilising the cognitive model in the conceptualization and assessment of school refusal behaviour avoids the need to confer a sick role by matching with existing diagnostic clinical syndromes, nor does it imply any blame on the child for refusing to go to school. Earlier attempts to explain school refusal with operant conditioning principles were found insufficient as the interactions between a behaviour and a reinforcer does not occur unconsciously [29], and more importantly this model failed to consider psychosomatic problems [30]. There will be ongoing cognitive processes that will recognise the links between contingent events, and thereafter integrate all available information relating to one's aptitude or self-assurance that the behaviour necessary to generate the desired outcomes can be successfully executed [31,32]. Self-efficacy was theorized to be the driving 
mechanism of a person's behaviour [31]. Selfefficacy affects self-regulation abilities [33], influences life satisfaction [34], determines the types of coping strategies adopted [35], and promote prosociality [36]. Deficits in any of these components commonly underlie the motivations of school refusal, so it can be projected that the lower one's perceived self-efficacy the higher the tendencies are to sustain the maladaptive behaviour.

Parallel to the functional model, the cognitive model also recognized how essential it was to create understanding on school refusal behaviour that extended beyond clinical symptoms. Expanding on Albert Bandura's triadic reciprocal model (human behaviours are influenced by cognition and other personal factors, as well as the environment), school refusal was viewed beyond the unidirectional operant conditioning of the functional model [29,37]. Events in the environment will be filtered by cognitive processes, which then confer meanings onto these external stimuli, conferring them with specific emotional bearing and motivating drive, which will be integrated into a cognitive model that would then guide judgment and behaviour [37]. The effects of these actions that were carried out then form a feedback loop, which would serve as a form of observational learning for modelling of future actions. The equation does not stop there because there would also a continuous and concurrent interplay of observational learning in the form of mimicry of behaviours observed in others or abstract modelling of rules embodied in these observed behaviours, motivational incentives, self-regulation, moral standards and self-reflectivity [37].

Mansdorf and Lukens (1987) [38] reported the earliest attempts to conceptualize school refusal behaviour in a combination of operant and cognitive processes. They described an intervention program carried out on 2 children with severe school phobia where the separation anxiety portrayed as the child's difficulty in regulating anxiety and environmental stimuli, whilst the manifestation of school refusal was maintained by the parents' reinforcing the child's maladaptive coping behaviour [38]. This notion was developed extensively by Heyne et al. (1998) in the form of the Self-Efficacy Questionnaire for School Situations (SEQ-SS) which explored the school refuser's beliefs on his ability to cope with various school-related circumstances as an initial step in formatting an individualized treatment plan [39].

\section{Self-Efficacy}

A person's functions (thoughts, feelings, actions and motivation) were observed to be controlled by self-regulatory mechanisms that were in continuous interaction with external sources of social norms and demands [32,40]. These processes of personal agency operates through self-monitoring, self-jugdment and self-reaction. Strongly influencing the system are one's beliefs about their abilities to attain specific goals or effect certain levels of performance, termed perceived self-efficacy [41]. This multidimensional phenomenon brings to light a dynamic anticipatory system involving cognitive processes that determines human functioning beyond the linear feedback of exogenous influences.

Perceived self-efficacy affects initiation and maintenance of behaviour via a two-component operational mechanism [32]; outcome expectancy, in which the individual estimates certain outcomes that would follow a behaviour, and efficacy expectations, determined by how confident the individual is that the behaviour to generate the outcomes can be successfully executed.

Even when an individual has ample motivation and skill to pursue a behaviour, efficacy expectations remains a major determinant of its execution [31]. Fear and avoidance of situations occur when an individual perceived the circumstances involved as exceeding his/ her skills. On the other hand, there is usually confident participation in activities if the situation is judged to be within the individual's capabilities. For the former group who cease their efforts prematurely, the fears and self-incapacitating expectations will further diminish their sense of efficacy. In the latter, experiences from the executed behaviours enhance individual sense of personal mastery, and eliminate negative defenses.

\section{Conclusion}

The existing theoretical basis of school refusal behaviour can be grouped into main schemes: firstly, symptomatic models; secondly is the operant conditioning model and thirdly, the cognitive model. Anxious school refuser fell under the symptomatic model because the focus had been on examining the child's mental health 
wellbeing, pathological parent-child relationships, difficulties in peer relationships and adverse experiences at home and/or in school, in relation to the school refusal behaviour. Moving away from symptomatic models that tend to medicalize the symptom of school refusal into a syndrome or disorder, the operant conditioning model acknowledged that school refusal is essentially a maladaptive behaviour that is motivated and maintained by positive and/or negative reinforcers. The more recent model was oriented towards cognitive processes of school refusers in which self-regulation of behaviours was postulated to be greatly influenced by one's perceived self-efficacy. These theories are combined into Figure 1.
Looking at the needs of the proper assessment to identify the problem in school refusal, it is useful if a standard assessment tool particularly for Malaysian population is developed in the future.

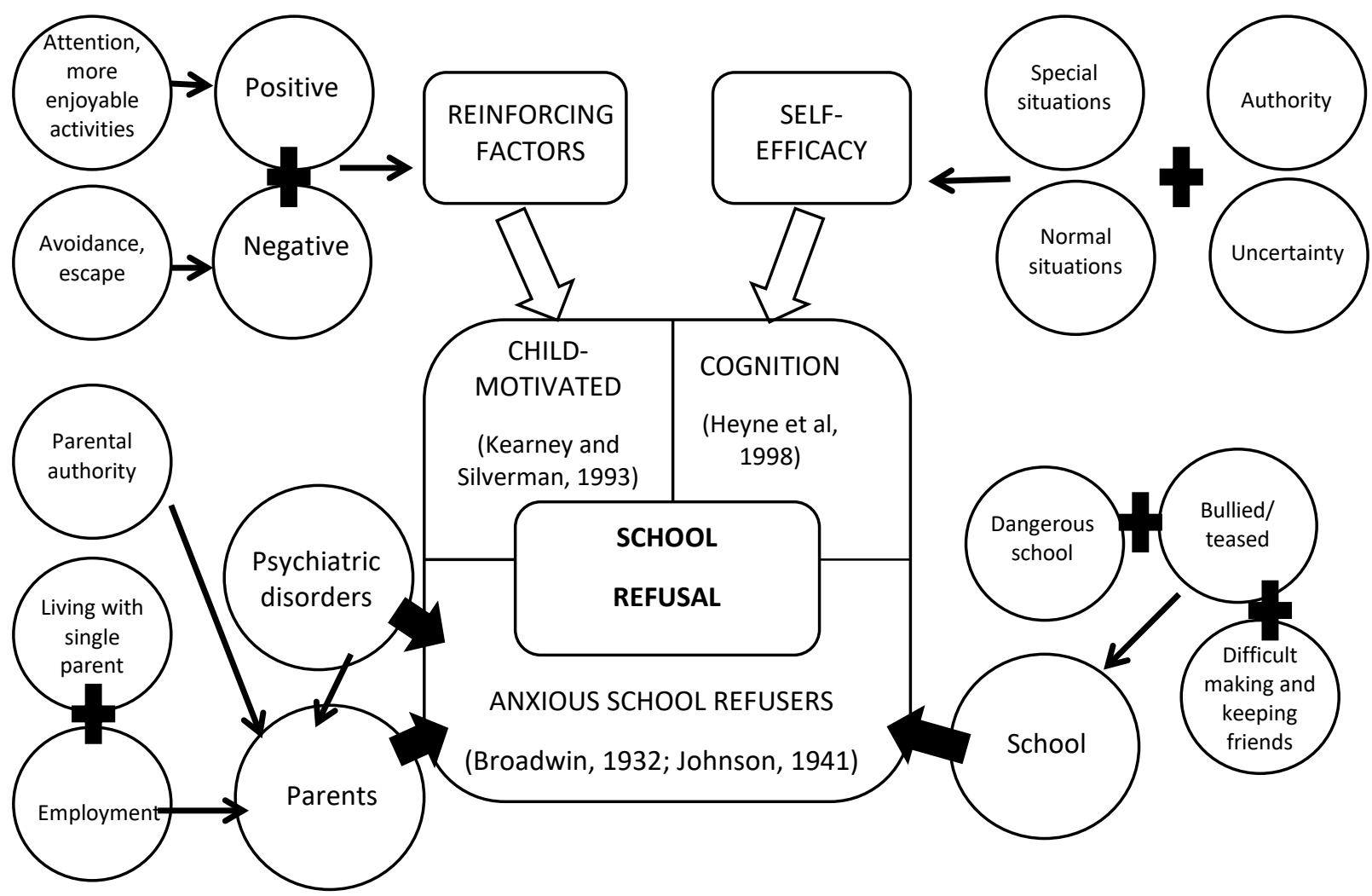

Figure 1. Theoretical framework summarizing the existing evidences on school refusal. 


\section{References}

[1] Heyne D, Sauter FM, Ollendick TH, Van Widenfelt BM, Westenberg PM. Developmentally sensitive cognitive behavioral therapy for adolescent school refusal: Rationale and case illustration. Clin. Child Fam. Psychol. Rev. 2014; 17(2): 191-215.

[2] Ministry of Education Malaysia. Malaysia Education Blueprint 2013 - 2025: Preliminary Report. 2013. Retrieved 10 August 2014 from:http://www.moe.gov.my/en/pelanpembangunan-pendidikan-malaysia-20132025.

[3] Carroll HT. The effect of pupil absenteeism on literacy and numeracy in the primary school. School Psychology International. 2010; 31(2), 115-30.

[4] Gresham FM, Vance MJ, Chenier J, Hunter K. Assessment and treatment of deficits in social skills functioning and social anxiety in children engaging in school refusal behaviors. In, Handbook of assessing variants and complications in anxiety disorders: Springer. 2013; pp 15-28.

[5] Christle CA, Jolivette K, Nelson CM. School characteristics related to high school dropout rates. Remedial and Special Education. 2007; 28(6), 325-39.

[6] King NJ, Tonge BJ, Heyne D, Pritchard M, Rollings S, Young D, Myerson N, Ollendick TH. Cognitive behavioral treatment of school refusing children: A controlled evaluation. J. Am. Acad. Child Adolesc. Psychiatry. 1998; 37(4), 395-403.

[7] Valles $E$, Oddy $M$. The influence of a return to school on the long-term adjustment of school refusers. J. Adolesc.1984;7(1), 35-44.

[8] Egger HL, Costello JE, Angold A. School refusal and psychiatric disorders: a community study. J. Am. Acad. Child Adolesc. Psychiatry. 2003; 42(7), 797-807.

[9] McShane G, Walter G, Rey JM. Characteristics of adolescents with school refusal. Aust. N. Z. J. Psychiatry. 2001; 35(6), 822-6.

[10] Kearney CA. School absenteeism and school refusal behavior in youth: A contemporary review. Clin. Psychol. Rev. 2008; 28(3), 451-71.

[11] Berg I. School refusal and truancy. Archives of disease in childhood. 1997; 76(2), 90-1.

[12] Hersov LA. Refusal to go to school. J. Child Psychol. Psychiatry. 1960; 1(2), 137-45.

[13] Gupta M, Lata P. . Absenteeism in Schools: A chronic problem in the present time. Educational Confab. 2014; 3(1), 11-16
[14] Thambirajah M, Grandison KJ De-Hayes L. Understanding school refusal: A handbook for professionals in education, health and social care. 2007: Jessica Kingsley Publishers.

[15] Inglés CJ, Gonzálvez-Maciá C, GarcíaFernández JM, Vicent $M$, MartínezMonteagudo MC. Current status of research on school refusal. European Journal of Education and Psychology. 2015; 8(1), 37-52.

[16] Lyon AR, Cotler S. Toward reduced bias and increased utility in the assessment of school refusal behavior: The case for diverse samples and evaluations of context. Psychology in the Schools. 2007; 44(6), 551-65.

[17] Wherry JN, Marrs AS. Anxious school refusers and symptoms of PTSD in abused children. Journal of Child \& Adolescent Trauma. 2008; 1(2), 109-17.

[18] Elliott JG. Practitioner review: School refusal: Issues of conceptualisation, assessment, and treatment. J. Child Psychol. Psychiatry. 1999; 40(7), 1001-12.

[19] Broadwin IT. A contribution to the study of truancy. American Journal of Orthopsychiatry. 1932; 2(3), 253-9.

[20] Johnson AM, Falstein El, Szurek S, Svendsen M. School phobia. American Journal of Orthopsychiatry. 1941; 11(4), 702.

[21] Lang M. School refusal an empirical study and system analysis. Australian Journal of Family Therapy. 1982; 3(2), 93-107.

[22] Berg I, Butler A, Franklin J, Hayes H, Lucas C, Sims R. DSM-III-R disorders, social factors and management of school attendance problems in the normal population. J. Child Psychol. Psychiatry. 1993; 34(7), 1187-203.

[23] Ek H, Eriksson R. Psychological factors behind truancy, school phobia, and school refusal: A literature study. Child \& Family Behavior Therapy. 2013; 35(3), 228-48. doi: 10.1080/07317107.2013.818899

[24] Yamazaki A. The medicalization and demedicalization of school refusal: Constructing an educational problem in Japan. Troubling children: Studies of children and social problems. 1994; 201-20.

[25] Skinner BF. Operant Behavior. In, Science and Human Behavior. New York: Collier Macmillan. 1953; pp 59 - 90.

[26] Kearney CA, Silverman WK. A preliminary analysis of a functional model of assessment and treatment for school refusal behavior. Behavior Modification. 1990; 14(3), 340-66.

[27] Kearney CA, Silverman WK. Measuring the function of school refusal behavior: The 
school refusal assessment scale. Journal of Clinical Child Psychology. 1993; 22(1), 85-96.

[28] Dube SR, Orpinas P. Understanding excessive school absenteeism as school refusal behavior. Children \& Schools. 2009; 31(2), 8795.

[29] Heyne D, King N, Tonge B, Rollings S, Pritchard $M$, Young $D$, Myerson N. The self-efficacy questionnaire for school situations: Development and psychometric evaluation. Behaviour Change. 1998; 15(1), 31-40.

[30] Havik T, Bru E, Ertesvåg SK. Assessing reasons for school non-attendance. Scandinavian Journal of Educational Research. 2015; 59(3), 316-36.

[31] Bandura A. Self-efficacy: Toward a unifying theory of behavioral change. Psychol. Rev. 1977; 84(2), 191-215.

[32] Bandura., A. Perceived Self-efficacy in cognitive development and functioning. Educational Psychologist. 1993; 28(2), 117-48.

[33] Bandura A, Caprara GV, Barbaranelli C, Gerbino M, Pastorelli C. Role of affective selfregulatory efficacy in diverse spheres of psychosocial functioning. Child development. 2003; 74(3), 769-82.

[34] Vecchio GM, Gerbino M, Pastorelli C, Del Bove G, Caprara GV. Multi-faceted self-efficacy beliefs as predictors of life satisfaction in late adolescence. Personality and individual differences. 2007; 43(7), 1807-18.

[35] Schwarzer R. Self-efficacy: Thought control of action: Taylor \& Francis.

[36] Caprara GV, Alessandri G, Eisenberg N. (2012). Prosociality: the contribution of traits, values, and self-efficacy beliefs. J. Pers. Soc. Psychol. 2014; 102(6), 1289.

[37] Bandura A. Social cognitive theory. Annals of Child Development. 1989; 6, 1-60.

[38] Mansdorf IJ, Lukens E. Cognitive-behavioral psychotherapy for separation anxious children exhibiting school phobia. J. Am. Acad. Child Adolesc. Psychiatry. 1987; 26(2), 222-5.

[39] Heyne D, Sauter FM. School refusal. In: Essau, CA. and Ollendick, TH. (eds.), The WileyBlackwell Handbook of The Treatment of Childhood and Adolescent Anxiety First ed. 2013: John Wiley \& Sons, pp 471-517.

[40] Bandura A. Social cognitive theory of selfregulation. Organizational behavior and human decision processes. 1991; 50(2), 24887.

[41] Bandura A. Self-efficacy: Wiley Online Library. 1994. 